\title{
Perancangan Inovasi Display Sepatu Fleksibel Untuk Meningkatkan Efisiensi Bagi Kebutuhan Sentra UKM
}

\author{
Anastasia Tertiara, Kathryn Immanuel, dan Grace Mulyono \\ Program Studi Desain Interior, Fakultas Seni dan Desain, Universitas Kristen Petra \\ Surabaya, Indonesia \\ e-mail : anastasiatertiara.4598@gmail.com
}

\begin{abstract}
Abstrak - Sentra UKM Merr membutuhkan inovasi pada display alas kaki karena adanya beberapa faktor yang menyebabkan produk tersebut tidak dilihat oleh para pengunjung, salah satunya adalah penataan dan bentuk display yang tidak efisien sehingga menyebabkan produk alas kaki kurang menarik. Oleh karena itu, penulis melakukan inovasi display alas kaki yang fleksibel untuk meningkatkan efisiensi penggunaannya. Metode yang dilakukan penulis adalah lima tahap desain menurut Henry Ford Learning Institute, yaitu understanding, observe, ideate, prototype, dan test. Berdasarkan lima tahapan desain tersebut, dirancanglah display alas kaki dengan konstruksi tertentu agar dapat mengubah bentuk display untuk disesuaikan dengan kebutuhan pengguna.
\end{abstract}

Kata kunci - UKM Merr, display, sepatu, fleksibel, inovasi

\begin{abstract}
Merr UKM Center requires innovation in footwear displays because of several factors that causes the product to not be seen by visitors, one of which is an inefficient arrangement and the form of the displays which causes footwear products to be less attractive. Therefore, the authors innovated a flexible footwear displays to improve the efficiency of their use. The method used by the author is the five stages of design according to the Henry Ford Learning Institute, namely understanding, observe, ideate, prototype, and test. Based on the five design stages, the footwear display is designed with a certain construction so that it can change the shape of the display to suit the user's needs.
\end{abstract}

Keywords — UKM Merr, display, shoes, flexible, innovation

\section{PENDAHULUAN}

Usaha Kecil dan Menengah (UKM) adalah istilah yang mengacu pada jenis usaha kecil yang memiliki kekayaan bersih paling banyak Rp 200.000.000,-, tidak termasuk tanah dan bangunan tempat usaha. Berdasarkan Keputusan Presiden RI no. 99 tahun 1998, pengertian Usaha Kecil ialah: "Kegiatan ekonomi rakyat yang berskala kecil dengan bidang usaha yang secara mayoritas merupakan kegiatan usaha kecil dan perlu dilindungi untuk mencegah dari persaingan usaha yang tidak sehat." Di Surabaya, UKM-UKM tersebut didukung dan dibantu oleh pemerintah dengan mendirikan sebuah tempat khusus yaitu Sentra UKM Merr. Sentra yang terletak di Jl. Ir. Soekarno no. 11, Surabaya, berperan sebagai ikon simbolik untuk UKM dan memiliki tujuan menumbuhkan dan mengembangkan usahanya dalam rangka membangun perekonomian nasional berdasarkan demokrasi ekonomi yang menghormati persamaan hak dan kewajiban dalam berusaha. Saat ini, terdapat kurang lebih 165 UKM yang bergabung dan memasarkan beragam produk melalui sentra UKM tersebut [1] dan [2].

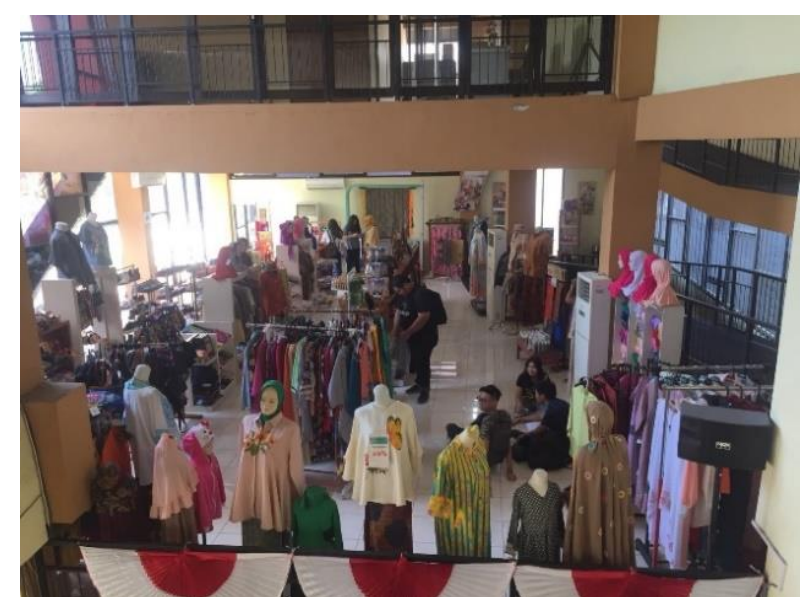

Gambar 1. Area penataan produk fashion.

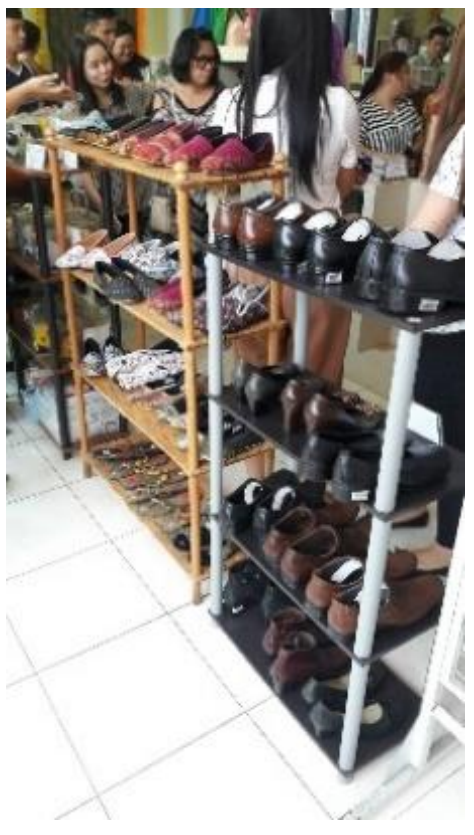

Gambar 2. Area display produk sepatu. 
Sentra UKM Merr yang menerima begitu banyak UKM perlu melakukan penataan display dagangan. Penataan display sangat penting dilakukan karena akan berpengaruh pada penjualan produk. Tujuan display adalah sebagai attention dan interest customer yang berarti menarik perhatian pengunjung yang datang. Penataan yang benar adalah produk yang dijual mudah dilihat, mudah dicari, mudah diambil, menarik dan aman.

Di Sentra UKM Merr, penataan produk dagangan diatur sesuai dengan jenis produk dan dibagi menjadi 3 kategori, sesuai tingkatan lantai pada bangunan tersebut (Gambargambar 1 dan 2). Lantai satu digunakan sebagai area kasir dan penjualan makanan maupun minuman. Lantai dua dimanfaatkan sebagai area penjualan produk fashion, mulai dari pakaian, alas kaki, hingga aksesoris fashion lainnya. Lantai tiga dimanfaatkan sebagai area penjualan kerajinan tangan, seperti keranjang, mainan, hingga lukisan. Namun, konfigurasi peletakan produk dan jenis furnitur yang digunakan tidaklah seragam dan tidak efisien. Hal ini menyebabkan beberapa dampak negatif, seperti adanya produk yang mengalami kerusakan karena terpapar cahaya matahari, ruangan yang berkesan sempit, dan kesan 'berantakan' akibat furnitur display yang tidak seragam [3], [4], dan [5].

Hal tersebut diatas akan dapat menimbulkan permasalahan sendiri bagi UKM, dimana produk yang dipajang tidak dapat terjual secara maksimal. Dengan adanya perancangan display rak sepatu fleksibel ini diharapkan dapat menjadi alternatif solusi bagi pengelola sentra UKM Merr dalam menata produk yang akan dijual pada ruang yang terbatas. Permasalahan yang teridentifikasi dapat dijabarkan berdasarkan beberapa faktor, yaitu performasi, fungsi, dan kualitas bentuk.

\section{Faktor performasi}

Faktor performasi meliputi permasalahan yang ada pada ruang yang mempengaruhi kenyamanan, kepraktisan, keamanan, kemudahan dalam penggunaan, kemudahan dalam pemeliharaan, dan kemudahan dalam perbaikan. Masalah yang teridentifikasi adalah keterbatasan ruang gerak pengunjung karena penataan yang tidak terorganisir sehingga membuat pengunjung tidak nyaman, area sepatu tidak terlalu diperhatikan oleh pengunjung karena produk sepatu merupakan produk dengan kuantitas yang minoritas jika dibanding dengan produk lain, furnitur display yang digunakan membahayakan pengunjung karena ruang gerak pengunjung terbatas dan ukuran furnitur yang besar.

Selain itu, untuk segi kemudahan furnitur yang digunakan kurang efisien karena furnitur display memiliki ukuran yang besar sehingga tidak mudah untuk dipindahkan, furnitur susah untuk dibersihkan karena tempat yang kurang memadai, dan jika produk mengalami kerusakan pengguna akan kesusahan karena tidak suku cadang yang tersedia sehingga perlu mengeluarkan biaya yang lebih untuk memperbaikinya.

\section{Faktor fungsi}

Faktor fungsi produk meliputi kelayakan produk dan kehandalan produk. Dari kelayakan produk teridentifikasi masalah berupa ketidaksesuaian dengan kebutuhan produk jual sehingga produk tidak memiliki perhatian khusus, dan dalam segi kehandalan produk kurang efisien karena terlalu banyak furnitur display yang digunakan [7].

\section{Kualitas bentuk}

Ada beberapa masalah yang teridentifikasi adalah estetika furnitur display yang digunakan tidak unity karena terlalu banyak perbedaan gaya furnitur yang digunakan dalam satu ruang.

\section{METODE PERANCANGAN}

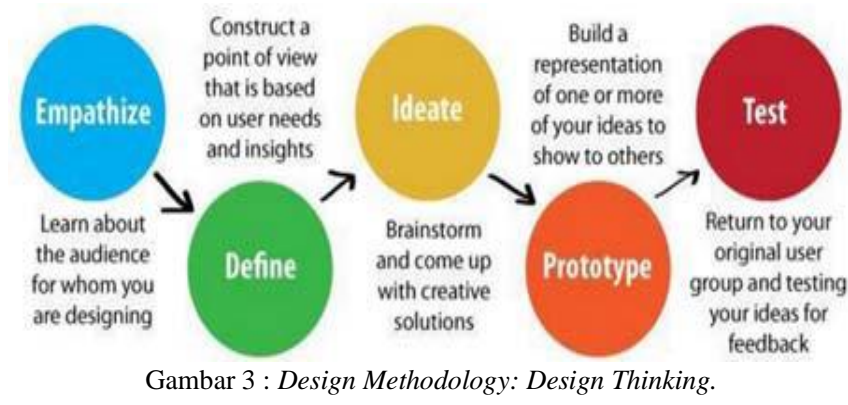

Perancangan ini dengan melakukan proses design thinking untuk menemukan inovasi desain yang baru (Gambar 3). Design thinking menurut Henry Ford Learning Institute meliputi 5 tahap [8], yaitu :

\section{Empathize}

Tahap empathize berfokus untuk memahami user tentang pemikiran, keinginan, dan kebutuhannya. Target luaran dari tahap ini adalah menemukan eksistensi masalah desain, dengan cara salah satunya melalui proses observasi, studi literatur dan tipologi. Penulis melakukan eksplorasi Sentra UKM Merr guna untuk memahami masalah desain pada ruang yang dituju. Selain itu, penulis juga mengeksplorasi data literatur dan data tipologi tentang produk interior, ruang komersial retail dan mall. Selain itu, penulis mencari data interior objek sentra UKM Merr yang berupa fisik dan nonfisik.

\section{Define}

Tahap define merupakan tahap untuk menemukan fokus dari permasalahan yang ditemukan dengan melalui proses analisa, dan programming.

Untuk desain produk, penulis melakukan analisa fungsi dan kenyamanan produk interior dan merumuskan konsep programming produk interior. Konsep yang dibuat merupakan solusi yang dapat menjawab permasalahan yang ditemukan.

Untuk desain ruang, penulis melakukan analisa pasar dan kebutuhan ruang, zoning, dan grouping. Hal ini dilakukan untuk membuat konsep programming ruang yang dapat menjawab permasalahan yang dirasakan oleh user.

\section{Ideate}

Tahap ideate merupakan tahap menemukan inovasi desain dengan melakukan brainstroming dan merumuskan konsep desain. Konsep desain tersebut akan diturunkan menjadi terapan-terapan solusi pada desain produk.

Untuk desain produk, di tahap ini penulis membuat sketsa konseptual yang terdiri dari beberapa alternatif ide atau konsep. Setelah itu, salah satu ide atau konsep desain dipilih untuk dilakukan beberapa alternatif pengembangan desain yang berupa sketsa dan maket studi (mock up). Dari beberapa alternatif tersebut, dipilih satu sebagai desain akhir. 
Untuk desain ruang, penulis melakukan re-design ruang yang merupakan hasil dari konsep programming ruang yang telah dirumuskan pada tahap define pada ruang yang dituju di Sentra UKM Merr.

\section{Prototype}

Tahap prototype merupakan tahap proses produksi ide konsep yang direalisasikan. Pada tahap ini, penulis melakukan proses produk dengan skala $1: 1$ dan melakukan beberapa revisi gambar yang diperlukan.

\section{Test}

Tahap test merupakan tahap menguji konsep yang memiliki solusi untuk menyelesaikan masalah yang telah dirumuskan pada tahap define.

Produk prototype di uji coba lalu kemudian dipamerkan untuk mengetahui apakah produk tersebut menjawab permasalahan yang ada dengan kriteria sebagai berikut :
a. Evaluasi kesesuaian solusi desain terhadap permasalahan
b. Evaluasi bentuk material
c. Evaluasi konstruksi
d. Evaluasi proses produksi

\section{HASIL DAN PEMBAHASAN}

\section{Konsep Desain}

Konsep perancangan digunakan sebagai pedoman dalam proses pencarian ide atau ideate yang didasarkan pada kebutuhan Sentra UKM dalam menunjang penjualan produk untuk menghasilkan solusi dari permasalahan yang teridentifikasi. Solusi tersebut meliputi :

1. Keringanan agar mudah dipindahkan,

2. Keseragaman bentuk yang cocok dengan berbagai macam produk dijual,

3. Fleksibilitas yang menyesuaikan dengan konsep interior dan kebutuhan display.

Solusi tersebut diwujudkan dalam bentuk ide konsep desain, yaitu penataan modular dan transformasi bentuk. Modular didefinisikan sebagai mixing and matching antar variasi komponen untuk membentuk atau mendukung kesatuan produk yang kompleks. Dengan adanya konsep modular ini, penataan akan lebih sederhana dan lebih murah [9]. Selain itu, komponen dapat disusun secara efektif menjadi produk baru yang dapat menyesuaikan kebutuhan konsumen yang berubah-ubah

Transformasi bentuk merupakan hasil dari perubahan benda melalui variasi-variasi yang timbul akibat manipulasi pada bentuk tersebut atau akibat penambahan maupun pengurangan elemen- elemennya.

Penataan modular dipilih untuk menciptakan bentuk produk yang dapat disusun secara fleksibel menyesuaikan kebutuhan Sentra UKM, sedangkan transformasi bentuk bertujuan untuk menyesuaikan luas ruang yang digunakan dan dapat dikonfigurasi agar dapat memaksimalkan ruang tersebut.

Konsep terinsipirasi dari sebuah mainan yang bernama infinity cube yang memiliki konstruksi penghubung khusus agar dapat berubah berbagai bentuk (Gambar 4).

Infinity cube memiliki konstruksi berupa engsel yang berjumlah 8 pasang. Pemasangan engsel ini diterapkan pada bagian tertentu. Sehingga, bentuk ini memiliki pergerakan yang fleksibel untuk menciptakan bentuk baru.

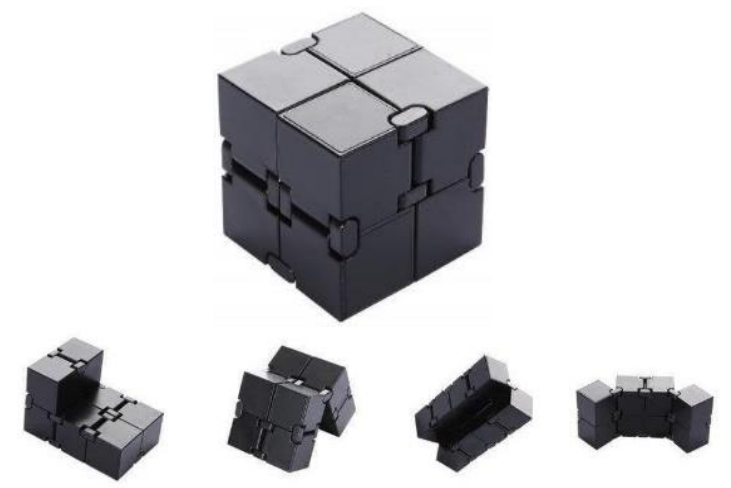

Gambar 4. Infinity Cube

\section{Material}
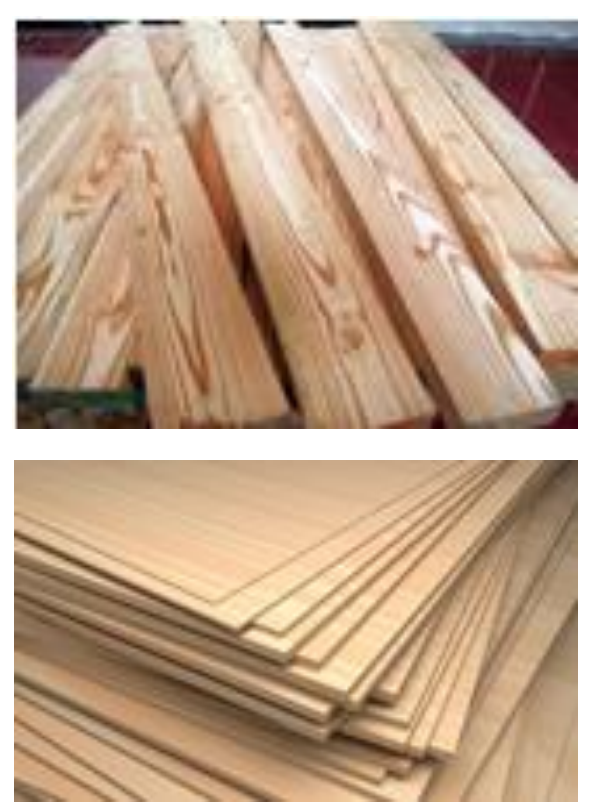

Gambar 5. Material kayu pinus dan triplek

Penggunaan material yang diperlukkan pada perancangan ini adalah jenis material yang memiliki sifat ringan dan kokoh. Kayu pinus digunakan sebagai material utama karena memiliki massa yang ringan dan kokoh. Kayu pinus atau kayu tusam ini merupakan kayu kelas kuat III, yang berarti memiliki kekokohan yang cukup. Selain itu, kayu ini memiliki warna coklat-kuning muda dengan garis serat yang berwarna lebih gelap (Gambar 5).

Pada alas display menggunakan material triplek. Pemilihan material ini didasari oleh sifat triplek yang ringan dan tipis, sehingga alas dapat dilepas dan pasang ketika furnitur display diubah bentuknya.

Selain material kayu, produk ini menggunakan engsel kupu atau engsel pintu untuk konstruksi sistem transformasinya. Engsel kupu dipilih karena memiliki pergerakan yang fleksibel hingga 360 derajat, sehingga furnitur display dapat diubah secara fleksibel (Gambar 6). 


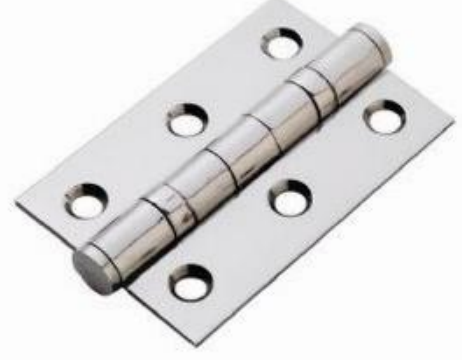

Gambar 6. Engsel kupu (engsel pintu).

\section{Batasan Desain}

Perancangan membutuhkan batasan desain agar dalam proses pembuatan desain tidak menjadi terlalu luas. Batasan-batasan tersebut yaitu produk memiliki desain yang sederhana, ringan sehingga mudah dipindahkan, fleksibel, memiliki konstruksi yang sederhana sehingga jika ada kerusakan pengguna dapat memperbaiki sendiri dan kontroksi tersebut memiliki ketahan dan kekuatan karena produk memiliki alternatif transformasi bentuk. Selain itu, produk harus memiliki penataan yang dapat dipindah-pindahkan dan dapat dilepas pasang dengan mudah.

\section{Transformasi Desain}

\section{Bentuk dasar}

Setelah melakukan design thinking, tercipta satu desain yaitu Infinity Box yang dapat dikonfigurasikan menjadi beberapa alternatif bentuk tergantung dari kebutuhan pengguna. Infinity Box memiliki bentuk dasar kubus yang memiliki ukuran 80 × $80 \times 80 \mathrm{~cm}$. Tiap box memiliki dimensi 40 x 40 $\mathrm{x} 40 \mathrm{~cm}$. Bentuk tiap box hanya dibentuk menyerupai kerangka, dengan tujuan agar furnitur display dapat digunakan pada tiap sisinya meskipun bentuk produk telah diubah menyesuaikan kebutuhan pengguna (Gambar 7).

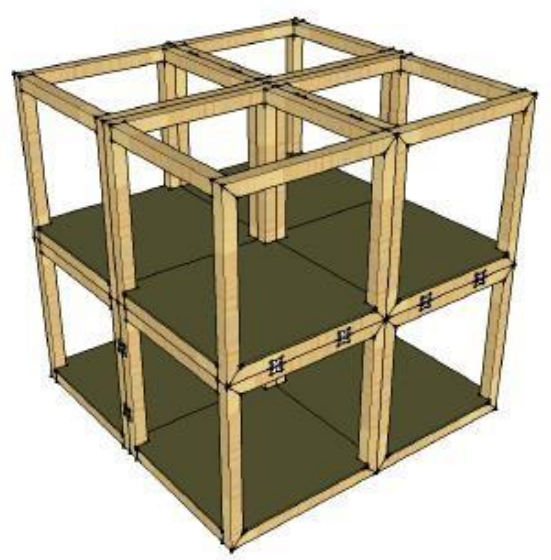

Gambar 7. Transformasi bentuk dasar produk.

\section{Bentuk untuk display produk-produk utama}

Infinity box memiliki pergerakan yang sangat fleksibel, sehingga furnitur display ini dapat diubah menjadi bentuk yang unik. Transformasi yang unik dapat menjadi daya tarik pengunjung yang datang, oleh karena itu infinity box dapat dijadikan etalase utama (Gambar-gambar 8 dan 9).

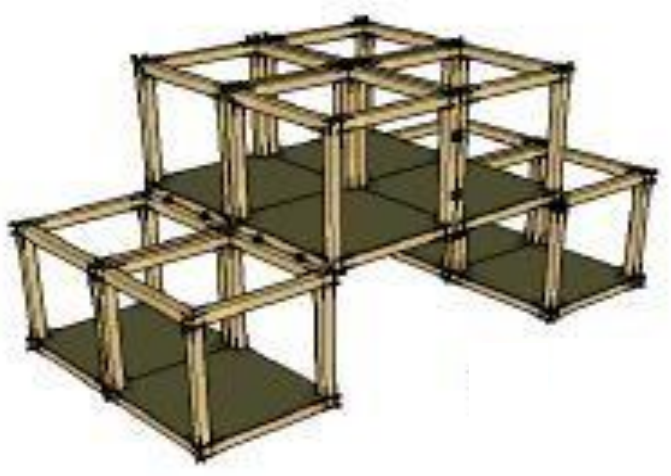

Gambar 8.Transformasi alternatif desain bentuk 1 .

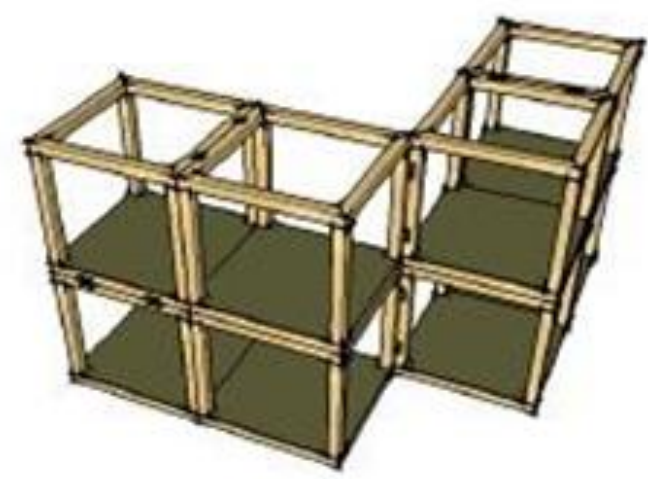

Gambar 9. Transformasi alternatif desain bentuk 2 .

\section{Bentuk lemari}

Jika furnitur display diubah menyerupai bentuk lemari, maka dimensi furnitur display adalah 40 × 80 × $160 \mathrm{~cm}$. Pada alternatif bentuk ini, pengguna dapat membentuk infinity box secara diagonal atau secara horizontal (Gambar-gambar 10 dan 11).

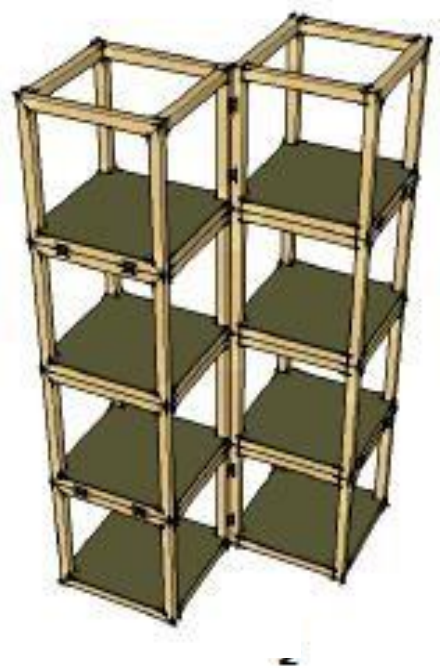

Gambar 10. Transformasi alternatif bentuk desain 3 . 


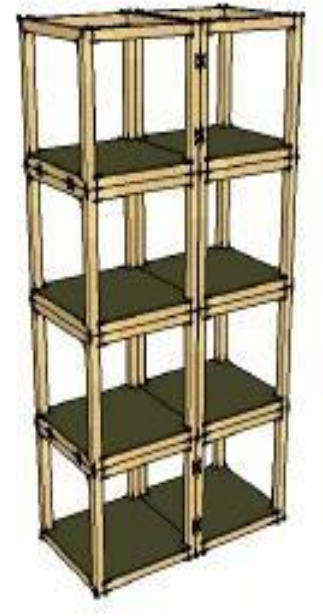

Gambar 11. Transformasi alternatif bentuk desain 4 .

\section{Desain Akhir}

Desain akhir dapat dilihat pada Gambar-gambar 12 dan 13.

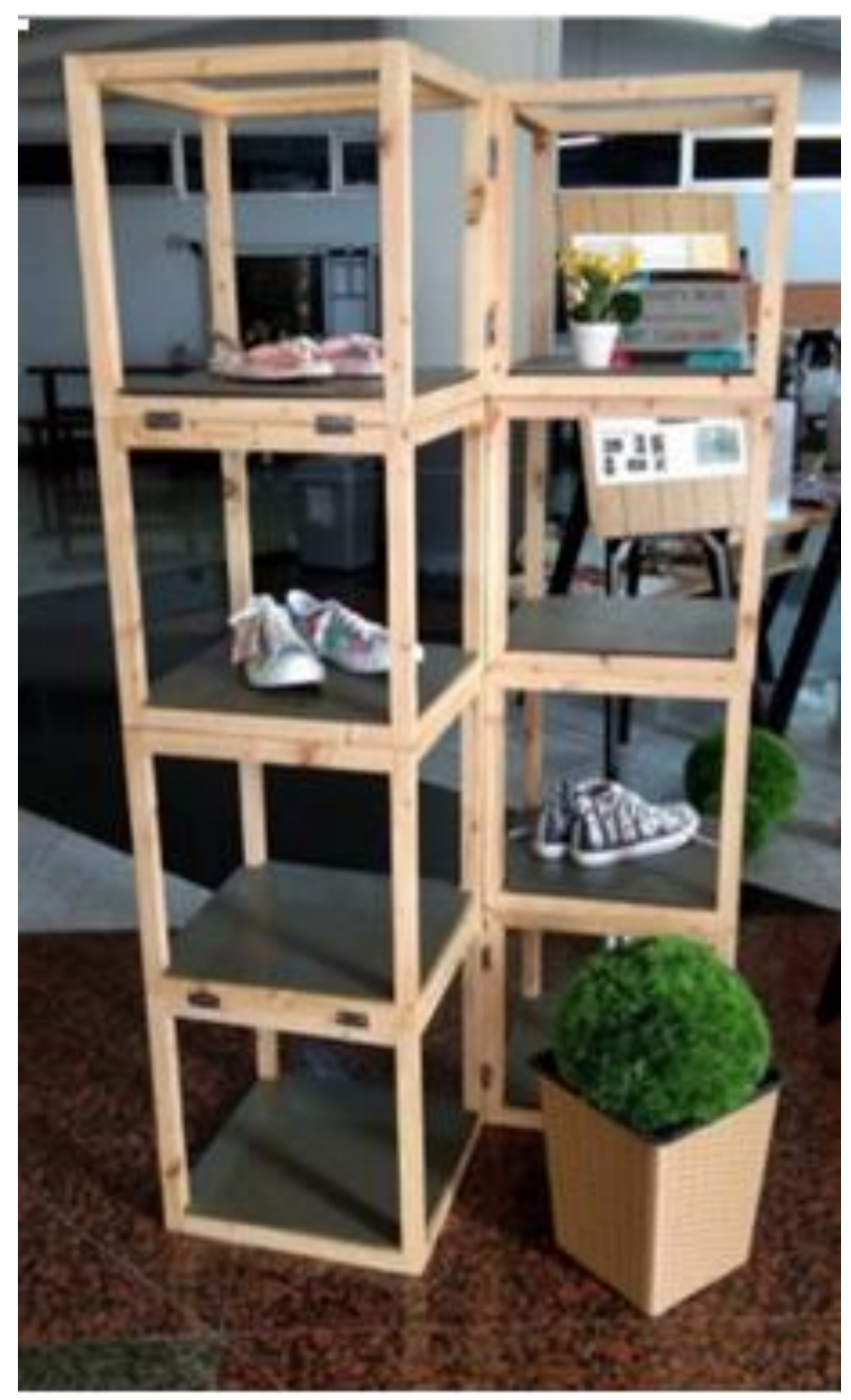

Gambar 12. Desain Akhir Infinity Box.

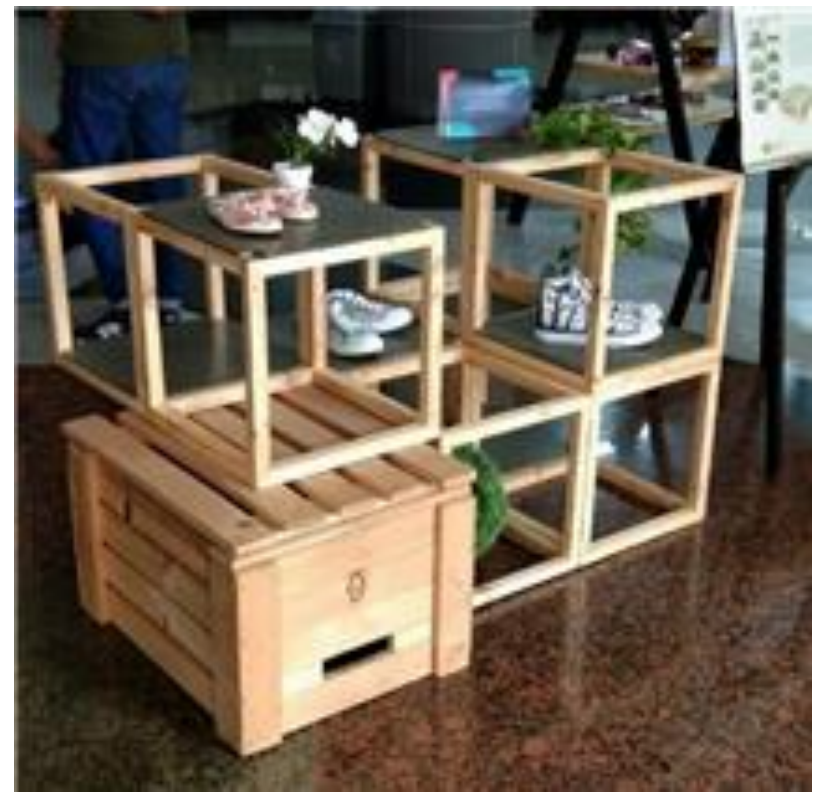

Gambar 13. Alternatif bentuk desain akhir Infinity Box.

\section{KESIMPULAN}

Keberagaman jenis produk UKM yang dipajang di Sentra UKM Merr menyebabkan permasalahan penataan produk jualan dan ketidak-seragaman furnitur display. Furnitur display yang digunakan harus dapat menyesuaikan dengan bentuk ruangan, jenis produk yang akan dipajang, dan perubahan pengaturan yang berbeda-beda sesuai kebutuhan. Oleh karena itu, penulis terinspirasi dari mainan Infinity Cube yang menawarkan ragam konfigurasi bentuk yang berasal dari satu bentuk dasar, yaitu kubus. Ide tersebut kemudian diimplementasikan menjadi rak display berupa kerangka kubus dengan material dasar kayu pinus yang kokoh namun ringan. Dengan bentuk sederhana dan konstruksi yang fleksibel, rak tersebut dapat memberikan pilihan konfigurasi bentuk rak sesuai kebutuhan.

\section{UCAPAN TERIMA KASIH}

Terima kasih diucapkan kepada pihak-pihak yang telah membantu dan membimbing penulis dalam proses perancangan furnitur display sepatu ini. Dan terima kasih pula untuk Sentra UKM Merr yang telah bekerja sama dengan Universitas Kristen Petra dalam mendukung pembelajaran mata kuliah Desain Produk Interior 3 ini.

\section{DAFTAR PUSTAKA}

[1] Liani, Chandra, https://docplayer.info/64294428-Bab-ipendahuluan-kecil-menengah-ukm-yang-dibangun-disurabaya-sentra-ukm-merr.html (2017). Diakses tanggal 9 Okt 2019.

[2] Sentra UKM Surabaya. http://sentraukmsurabaya.blogspot.com/ (2015). Diakses tanggal 21 November 2019. 
[3] Weny, A., "Desain Modular Dan Pengaruhnya Terhadap Waktu, Biaya, Dan Persediaan (Studi Kasus Stand Pameran Cv X)". Prosiding Seminar Nasional Manajemen Teknologi VIII. 2 Agustus 2008, Surabaya, Indonesia. Hal. A-17-2. (2008).

[4] Parliana, D., "Kajian Transformasi Bentuk dan Tatanan Massa Bangunan di Kawasan Bandung Super Mall”. Institut Teknologi Nasional. Bandung. (2017).

[5] Pemerintah Provinsi Jawa Timur, "Peraturan Daerah Provinsi Jawa Timur Nomor 6 Tahun 2011: Peraturan Daerah Tentang Pemberdayaan Usaha Mikro, Kecil, Dan Menengah". (2011).

[6] Mansyur, M., dkk, "Petunjuk Praktis Sifat-sifat Dasar Jenis Kayu Indonesia. Edisi 3". Indonesian Sawmill And
Woodworking Association (ISWA) dan ITTO. Indonesia. (2008).

[7] Wagiri, W, Santosa, A, Priyo, F., "Kajian dan Perancangan Mebel Fleksibel pada Retail Sepatu dan Tas Bergaya Modern”. Jurnal Intra. 2 (2): 648-654. (2014).

[8] Dewi, SK, Haryanto EK, dan De Yong, S., "Identifikasi Penerapn Design Thinking dalam Pembelajaran Perancangan Desain Interior Kantor. Seminar Nasional Seni dan Desain: Konvergensi Keilmuan Seni Rupa dan Desain Era 4.0". 25 Oktober 2018, Surabaya, Indonesia. Hal. 33-38. (2018).

[9] Ulrich, Karl T dan Eppinger, Steven D, "Perancangan dan Pengmbangan Produk”, Salemba Teknika (2000). 